Portland State University

PDXScholar

\title{
Effects of Oral and Silent Reading on the Reading Comprehension Performance of Left Hemisphere- damaged Individuals
}

Paul K. Akers

Portland State University

Follow this and additional works at: https://pdxscholar.library.pdx.edu/open_access_etds

Part of the Speech and Rhetorical Studies Commons

Let us know how access to this document benefits you.

Recommended Citation

Akers, Paul K., "Effects of Oral and Silent Reading on the Reading Comprehension Performance of Left Hemisphere-damaged Individuals" (1995). Dissertations and Theses. Paper 4964.

https://doi.org/10.15760/etd.6840

This Thesis is brought to you for free and open access. It has been accepted for inclusion in Dissertations and Theses by an authorized administrator of PDXScholar. Please contact us if we can make this document more accessible: pdxscholar@pdx.edu. 
The abstract and thesis of Paul $\mathrm{K}$. Akers for the Master of Science in Speech Communication: Speech and Hearing Science were presented February 9, 1995, and accepted by the thesis committee and the department.

COMMITTEE APPROVALS: Marié T. Rat, Co-Chair

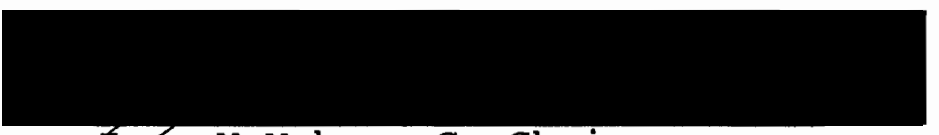

toán McMahon, Co-Chair

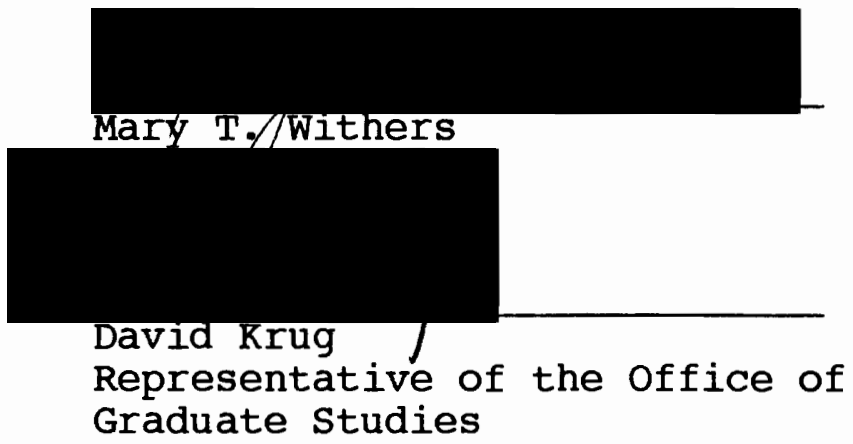

DEPARTMENT APPROVAL:

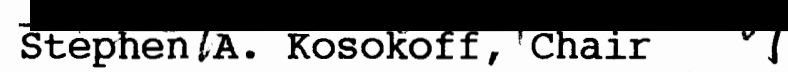
Department of Speech Communication

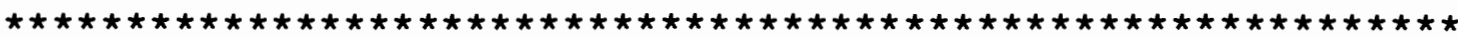

ACCEPTED FOR PORTLAND STATE UNIVERSITY BY THE LIBRARY by

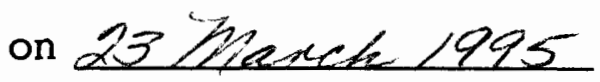




\section{ABSTRACT}

An abstract of the thesis of Paul K. Akers for the Master of Science in Speech Communication: Speech and Hearing Science presented February 9, 1995.

Title: Effects of Oral and Silent Reading on the Reading Comprehension Performance of Left HemisphereDamaged Individuals.

The purpose of this study was to examine whether or not the method of reading (either aloud or silently) would affect the reading comprehension performance of left hemispheredamaged (LHD) and non-brain-damaged (NBD) subjects across inference levels using the Nelson Reading Skills Test (NRST) (Hanna, Schell, \& Schreiner, 1977). The experimental group was comprised of fifteen subjects who had suffered a cerebrovascular accident (CVA) to the left hemisphere of the brain. Subjects were selected after they had demonstrated an adequate level of function on the Short Porch Index of Communicative Ability (SPICA) (DiSimoni, Reith, \& Darley, 1980), to perform the tasks required in this study. Subjects were then randomly assigned to either "left hemispheredamaged aloud reading" or "left hemisphere-damaged silent reading" subgroups. The non-brain-damaged (NBD) control group consisted of fifteen individuals with no known history of neurological impairment. Control group subjects were also 
randomly assigned to either the "non-brain damaged aloud reading" subgroup or the "non-brain damaged silent reading" subgroup. All subjects were administered the revised version of the Nelson Reading Skills Test (NRST) (1977), Form 4 of Level B. NRST test questions can be grouped into three categories representing literal, translational, and high levels of inference. Subjects were required to read five paragraphs and answer thirty-three questions pertaining to the reading material by pointing to the correct answer from a list of four choices. Subjects were allowed to refer back to the paragraph when attempting to answer test questions.

Results revealed total NRST performance to be significantly better for NBD subjects. Within both experimental and control groups, no significant difference was found to exist between the test scores of the oral and silent reading subgroups. The research data did not reflect the expected error pattern of most errors occurring on high inference level questions and fewest errors on literal inferences for either group of subjects. 
EFFECTS OF ORAL AND SILENT READING ON THE READING COMPREHENSION PERFORMANCE OF LEFT HEMISPHERE-DAMAGED INDIVIDUALS

by

PAUL K. AKERS

A thesis submitted in partial fulfillment of the requirements for the degree of

MASTER OF SCIENCE

in

SPEECH COMMUNICATION :

SPEECH AND HEARING SCIENCE

Portland state University

1995 


\section{ACKNOWLEDGMENTS}

I wish to express my appreciation to a number of individuals who have been invaluable to me throughout this project.

Dr. Marie T. Rau, for without her guidance, support and encouragement this study would not have been possible. I would also like to thank Joan McMahon for her contribution to this project and for serving as my advisor throughout my program at Portland State University. A debt of gratitude is also owed to my other committee members, Mary T. Withers and David Krug. Their comments and suggestions substantially improved the quality of this study.

The staff of the Speech Pathology Section at the Portland Veterans Affairs Medical Center for all of their assistance in helping me to recruit subjects for this project.

A special thanks to Dr. Robert Fountain at Portland State University Statistics Department for assisting me with the statistical analysis.

I would also like to thank all of the family members and friends who have provided me with tremendous moral support throughout the course of this project.

Finally, a heart-felt thank you to those individuals who took time out of their day to participate in this study. Their efforts are truly appreciated. 
TABLE OF CONTENTS

PAGE

ACKNOWLEDGMENTS $\ldots \ldots \ldots \ldots \ldots \ldots \ldots \ldots \ldots \ldots \ldots \ldots \ldots \ldots$

LIST OF TABLES $\ldots \ldots \ldots \ldots \ldots \ldots \ldots \ldots \ldots \ldots \ldots \ldots \ldots \ldots \ldots$

LIST OF FIGURES $\ldots \ldots \ldots \ldots \ldots \ldots \ldots \ldots \ldots \ldots \ldots \ldots \ldots \ldots \ldots$

CHAPTER

I INTRODUCTION AND STATEMENT OF PURPOSE ........

Introduction $\ldots \ldots \ldots \ldots \ldots \ldots \ldots \ldots \ldots \ldots \ldots \ldots$

Statement of Purpose ............... 5

Definition of Terms $\ldots \ldots \ldots \ldots \ldots \ldots$

II REVIEW OF THE LITERATURE ................. 9

Reading Comprehension and Aphasia ....... 9

Attention and Aphasia ............... 14

Inference and Reading in Aphasia ....... 17

III METHODS AND PROCEDURES ................. 28

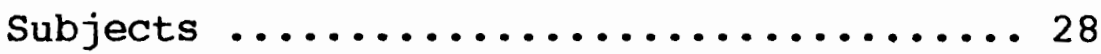

Human Subject Procedures............. 30

Testing Instruments $\ldots \ldots \ldots \ldots \ldots \ldots \ldots$

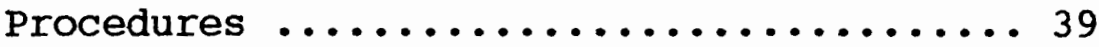

Measurements and Data Analysis ........4 40

IV RESULTS AND DISCUSSION ................ 42

Results ........................ 42

Discussion $\ldots \ldots \ldots \ldots \ldots \ldots \ldots \ldots \ldots \ldots$

V SUMMARY AND IMPLICATIONS ............... 53

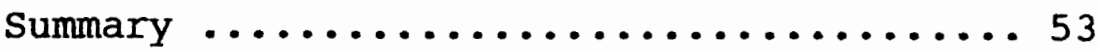

Clinical Implications .............. 54 
Implications for Further Research......... 55

REFERENCES 56

APPENDICES

A HUMAN SUBJECTS COMMITTEE APPROVAL $\ldots \ldots \ldots \ldots 61$

B CONSENT FORMS $\ldots \ldots \ldots \ldots \ldots \ldots \ldots \ldots \ldots \ldots \ldots 64$

C SHORT PORCH INDEX OF COMMUNICATIVE ABILITIES TEST PROTOCOL $\ldots \ldots \ldots \ldots \ldots \ldots \ldots \ldots \ldots \ldots$

D EXAMPLE OF NRST PARAGRAPHS AND TEST QUESTIONS $\ldots 72$

E TEST INSTRUCTIONS $\ldots \ldots \ldots \ldots \ldots \ldots \ldots \ldots \ldots$

F REVISED NRST SCORE SHEET $\ldots \ldots \ldots \ldots \ldots \ldots \ldots \ldots 92$ 


\section{LIST OF TABLES}

TABLE

PAGE

1 Descriptive Characteristics of Left BrainDamaged (LHD) Subjects ............. 29

2 Descriptive Characteristics of Non-Brain-

Damaged (NBD) subjects ............. 31

3 Comparison of Descriptive Characteristics for

LHD Subgroups $\ldots \ldots \ldots \ldots \ldots \ldots \ldots \ldots \ldots \ldots$

4 Summary of Descriptive statistics for NBD

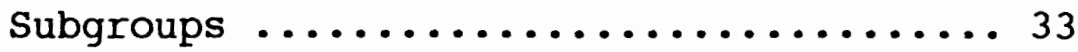

5 Summary of $t$-tests for Independent Means for

Age, Education, Time Post CVA,

and SPICA (Experimental Group)........ 35

6 Summary of $t$-tests for Independent Means for

Age and Education (Control Group) ..... 36

7 Summary of $t$-tests for Independent Means for

Age and Education (NBD and LHD Groups) ... 37

8 Summary of Descriptive Statistics for Experimental

Subject NRST scores ...............43

9 Summary of Descriptive Statistics for Control

Group NRST Scores ................. 44

10 Summary of the Analysis of Variance with Repeated

Measures by Question Type within and

Between Groups ..................448 


\section{LIST OF FIGURES}

FIGURE

PAGE

1. Mean percentage correct scores for left Hemisphere-Damaged and Non-BrainDamaged subjects on test items of the Nelson Reading Skills Test (NRST) by Level of Inference 
INTRODUCTION AND STATEMENT OF PURPOSE

\section{INTRODUCTION}

In our modern, technologically advanced society the ability to read and comprehend written language represents an invaluable skill that people use on a daily basis. Individuals rely on reading abilities to accomplish a variety of tasks and goals including gathering information, entertainment, vocational endeavors and a host of other purposes. It is difficult to overstate the degree to which people rely on their ability to comprehend written material. Given the importance placed on this skill, it becomes clear just how devastating the loss of comprehension is for those individuals stricken with aphasia.

The clinical term aphasia denotes an impairment of language which disturbs linguistic function across several modalities. Reading, however, may represent one modality which is particularly vulnerable to disruption. Webb and Love (1983) reported that nearly all aphasic adults have some degree of residual reading impairment even a year or more post onset of their brain injury.

It follows then that reading comprehension represents a fundamental linguistic skill and one which must be assessed in a comprehensive manner in persons with aphasia. The question then becomes, how does the clinician accurately 
assess reading comprehension in the aphasic population? Nearly all of the standard aphasia test batteries contain subtests to assess reading comprehension at the paragraph level (Nicholas, MacLennan, \& Brookshire, 1986). Over the past few years however, some researchers have begun to question the validity of commonly administered aphasia instruments in the assessment of multiple sentence reading comprehension. One indicator that has been employed for measuring test validity is the passage dependency index (PDI). Simply stated, passage dependency refers to the extent to which readers must rely on information supplied in the passage itself to correctly answer questions about the information contained in the passage. The more one must rely on information presented in the passage, the greater the level of passage dependency.

Using the PDI as an measure of validity, Nicholas et al.(1986), examined five of the more widely administered aphasia batteries. These included, the Boston Diagnostic Aphasia Examination (BDAE) (Goodglass \& Kaplan, 1983), the Minnesota Test for Differential Diagnosis of Aphasia (MTDDA) (Schuell, 1965), Examining for Aphasia (EFA) (Eisenson, 1954), the Reading Comprehension Battery for Aphasia (RCBA) (LaPointe \& Horner, 1979) and the Western Aphasia Battery (WAB) (Kertesz, 1982). The low level of passage dependency yielded by all five of these test batteries led to the conclusion that these instruments were not likely to be valid 
indicators of the reading comprehension abilities of either aphasic or non-brain damaged individuals. Furthermore, Nicholas et. al., (1986) state that in order for clinicians to obtain valid assessments of reading comprehension in aphasic adults, they must look to other supplemental reading tests. Based on its comprehensive sampling of reading performance and relatively high passage dependency, these researchers recommended the use of the Nelson Reading Skills Test (NRST) (Hanna, Schell, \& Schreiner, 1977), for the assessment of aphasic adults' reading comprehension in multiple sentence reading tasks.

In a subsequent study, Nicholas and Brookshire (1987) employed the NRST to evaluate the reading comprehension of aphasic and non-brain damaged individuals. The ability to make inferences or, to move beyond the factual or literal meaning of a text, is an essential component of comprehension (Graville \& Rau, 1990). The NRST is designed to measure reading comprehension at three levels of inference (literal, moderate or translational, and high). Test items which require higher levels of inference are significantly more difficult then those requiring literal or moderate levels and are therefore more often answered incorrectly. Results confirmed this error pattern with both non-brain damaged and aphasic subjects performing significantly better on literal and translational test items when compared to those requiring a high level of inference. These findings would appear to 
indicate that the NRST represents an effective instrument for assessing aphasic reading comprehension across levels of inference.

Subsequent studies by Graville \& Rau (1990) and Rau, Kongsbak, Gordon \& Graville (1992), on the other hand, reported finding no significant difference in subject performance across levels of inference using the NRST. In each of these studies, both the control and experimental groups made nearly as many errors on literal test items as they did on those requiring high levels of inference. The lack of agreement in findings between Nicholas and Brookshire (1987) and Graville \& Rau (1990), and Rau et al. (1992) raises the question of whether or not the NRST is, in fact, sensitive enough to measure reading comprehension of aphasic adults across inference levels.

Methodological differences have been cited as one probable reason for this disparity in findings (Rau et al., 1992). Both Rau and Graville (1990), and Rau et al.(1992), employed a methodology whereby subjects read the test material aloud. In contrast, Nicholas and Brookshire instructed subjects to read all passages and questions silently. It has been hypothesized by Rau et al.(1992) that reading aloud may have in fact, diverted attentional resources away from the content of the stimuli thereby reducing subject performance on low level inference items. 
STATEMENT OF PURPOSE

The purpose of this study is to determine whether or not the method of reading (either aloud or silently) influences subject performance across inference levels using the Nelson Reading Skills Test. The following hypothesis, stated in the null form, will be investigated:

There will be no significant difference in performance across inference levels between those subjects who read test materials silently and those who read materials aloud.

In testing the above hypothesis, the following two questions will be addressed:

1) Will left-hemisphere damaged and non-brain damaged subjects commit significantly more errors on the Nelson Reading Skills Test when reading aloud or when reading silently?

2) Will left-hemisphere damaged and non-brain damaged subjects commit significantly more errors on high inference level questions as compared to low inference level questions when reading aloud or when reading silently? 
DEFINITION OF TERMS

Before embarking on a review of the literature pertaining to reading comprehension after brain damage, it is important to first provide the reader with operational definitions of the terms used in this study.

anterior - Section of the brain which is in front of the Central Sulcus (Fissure of Rolando)

anomic aphasia - Aphasic syndrome characterized by word retrieval difficulties in spontaneous speech and naming tasks (Brookshire, 1992).

aphasia - A deficit in encoding and decoding of linguistic information caused by damage to the areas of the brain responsible for language (Kongsbak, 1990).

attention - Mental effort which is directed toward a particular task or tasks.

attentional resources - The supply or amount of mental effort which is available for allocation to a particular task or tasks.

brain damage - In the present study, this term is limited to neuropathological changes resulting from a cerebrovascular accident (stroke) to the left hemisphere of the brain.

Broca's aphasia - Aphasic syndrome associated with damage to Broca's area of the brain. Speech is typically 
agrammatic and telegraphic.

cerebrovascular accident - A disruption of bloodflow to the brain resulting in damage to the surrounding cerebral tissue.

conduction aphasia - Aphasic syndrome marked by a disproportionate difficulty in repeating what is said. Persons with conduction aphasia usually demonstrate good language comprehension skills.

high level inference - Items involving this type of inference require the reader to "identify cause and effect relationships, make judgments about events and attitudes of characters, and form bridging assumptions between information in the passage and correct answers" (Nicholas \& Brookshire $1987)$

inference level - Degree of cognitive and linguistic processing required to extract meaning from a given text. isolation (mixed transcortical) aphasia - Aphasic syndrome characterized by a lack of spontaneous speech with an intact ability to repeat what is said.

literal inference level items- Test items which may be answered directly from information explicitly stated in the reading passage to which the test question refers (Nicholas \& Brookshire, 1987).

reading comprehension - The ability to perceive, process and understand the meaning of written language (Kongsbak, $1990)$ 
posterior - Section of the brain which lies behind the Central Sulcus (Fissure of Rolando).

transcortical sensory aphasia - Aphasic syndrome marked by fluent, empty speech and reduced auditory comprehension. Individuals may exhibit a tendency to repeat virtually everything that is said in their presence (Brookshire, 1992). translational inference level item- Those which require the reader to "draw simple inferences, choose a synonym, or determine the correct referent for a pronoun" (Nicholas \& Brookshire, 1987, p. 358).

Wernicke's Aphasia - Aphasic syndrome in which speech is typically fluent while lacking content or meaning. Individuals with Wernicke's aphasia are significantly impaired in their ability to comprehend language and may experience problems with word retrieval. 
CHAPTER II

REVIEW OF THE LITERATURE

READING COMPREHENSION AND APHASIA

The majority of studies examining reading comprehension abilities in persons with aphasia have been designed to test reading comprehension skills at the word or sentence level. Gardner and Zurif (1976), examined the reading comprehension skills of aphasic persons at these levels in a set of four studies. Tasks included matching single words to pictures as well as matching pictures to sentences of increasing syntactic complexity and varying syntactic form. For purposes of comparison, subjects were categorized according to site of lesion as either anterior or posterior. Results indicated that anterior patients were able to comprehend sentences which posterior patients could not. While all aphasic subjects demonstrated impairment on the above tasks, matching single words to pictures was relatively easy compared to those tasks that demanded more complex linguistic judgments. Gardner \& Zurif also found that aphasic subjects performed considerably better on tasks which involved picturable nouns and experienced the greatest difficulty with tasks involving verb form.

A second study examining reading comprehension at the word and sentence level in aphasic subjects was conducted by Kertesz (1979), and was designed to determine the extent of 
reading disability in various aphasic groups. Two hundred and twenty five patients, classified according to type of aphasia based on performance on spoken language tasks, were evaluated on nine reading comprehension subtests. It was found that conduction and anomic aphasics achieved the highest reading comprehension scores while subjects with Broca's aphasia scored significantly better then those who demonstrated isolation (mixed transcortical), transcortical sensory or Wernicke's aphasia.

In a second study, Kertesz (1979), examined the relationship between reading aloud and reading comprehension in aphasic patients. A total of 56 subjects who had previously been diagnosed as demonstrating Broca's, conduction, Wernicke's, and global aphasia were given a card with six commands of increasing complexity printed on it. Subjects were instructed to read the card aloud and follow the command. Of the 14 Broca's patients, six were able to perform the commands better when they could read them aloud. Both subjects with conduction aphasia were able to read aloud and perform the command. All individuals demonstrating Wernicke's and global aphasia had difficult reading aloud or performing the command.

The results of these two studies indicate that reading is impaired in all individuals with aphasia. Regardless of taxonomic classification, reading scores of aphasic subjects were consistently below those of non-brain damaged subjects. 
Among groups of aphasic subjects, however, considerable variation was found to exist. Those individuals demonstrating anomic and conduction aphasia achieved the highest overall reading scores while global, mixed transcortical and Wernicke's subjects posted the lowest.

The reading skills of chronic aphasic individuals were investigated in a study by webb and Love (1983). A total of 35 aphasic subjects, all of whom were more then 1 year post onset, were given a battery of 12 reading tests designed to assess recognition, comprehension and oral reading at the word, sentences, and paragraph level. Of these three types of tasks, reading comprehension tests were found to be the most difficult for aphasic subjects, with oral reading items producing the next highest rate of error. In addition, subject performance on recognition tasks tended to support the findings of Gardner and zurif (1976) since subtests involving picturable nouns produced the lowest error rates. One of the most interesting outcomes of this investigation was that the severity of subjects' overall reading deficit was highly related to their ability to read aloud. The authors state that this relationship between the ability to read aloud and the ability to perform silent reading tasks of recognition and comprehension is probably dependent upon the presence of a verbal expressive language disorder. As these researchers point out, most theories of 
reading assume that expressive language development is a basic prerequisite for adequate reading skill. Theories differ, however, with respect to how written information is processed. Based on a model constructed by Laberge and Samuels (1974), Webb and Love (1983) speculate that individuals with aphasia lose the ability to automatically decode words as fluent readers do, and must therefore rely on the more controlled grapheme-to-phoneme conversion method for comprehending meaning.

Finally, it is important to note that all 35 aphasic subjects demonstrated some degree of residual reading deficit with no subject obtaining a perfect score. Regardless of test score, all subjects reported reading to be a slow, laborious process which they no longer found pleasurable since their brain insult.

The reading comprehension skills of aphasic adults on paragraph length material was examined by Nicholas and Brookshire (1987) using the Nelson Reading Skills Test (NRST) (Hanna, Schell, \& Schreiner, 1977). The NRST is designed to test reading comprehension at three inference levels: Literal, moderate or translational, and high. The performance of both the aphasic and non-brain damaged control groups varied depending upon the level of inference required. Both groups performed significantly better on low or literal items than they did on questions requiring a high level of inference. Aphasic subjects, however, did not 
differ in their performance on literal and translational questions, doing equally well on both. It is important to note, however, that despite exhibiting the same pattern of error, non-brain damaged subjects did perform better then aphasic subjects across all levels of inference.

In a subsequent study incorporating the design of Nicholas and Brookshire (1987) and using the same test instrument, Graville and Rau (1990) examined reading comprehension in patients with probable Alzheimer's dementia. Although the non-brain damaged control sample performed significantly better across all levels of inference when compared to the demented subjects, neither group demonstrated a significant difference in performance across the three inference levels.

A third study using this same design was conducted by Rau, Kongsbak, Gordon \& Graville (1992). These researchers investigated the comprehension of inferential reading material in both left and right hemisphere brain-damaged subjects. Again, both groups failed to demonstrate the expected error pattern of most difficulty on high inference level items, less on translational, and fewest errors on literal items. These investigators hypothesized that this disparity in findings may be attributable to the fact that subjects in the Nicholas and Brookshire study (1987) had read test material in a silent manner while in the 
investigations of Graville and Rau (1990) and Rau et al. (1992), subjects were instructed to read all material aloud. Therefore, this methodological difference in test administration may have resulted in a diversion of attentional resources away from the stimuli content in the latter two studies.

\section{ATTENTION AND APAHSIA}

Several theories have been developed in an effort to explain how attention is organized and directed. Perhaps the most influential and widely accepted model is the one proposed by Kahneman (1973). This model contains two fundamental assumptions. First, that "there is a general limit on capacity to perform mental work." second, that "this limited capacity may be allocated with considerable freedom among concurrent activities" (Kahneman, 1973, p.8). Therefore, Kahneman's model consists of a central pool of attention which is shared by all or several sensory, integrative and motor operations across all or several modalities (McNeil, 1983). At the center of this model is an allocation mechanism which serves to direct attentional resources. Building upon this model, McNeil (1991) has proposed an integrated attention theory of aphasia. Central to this theory is the belief that aphasia is the outcome of disturbances to language performance not language competence and that this performance is variable over time. This variability is due in part to the aphasic person's inability to consistently 
allocate adequate attention to a linguistic task.

Guided by McNeil's theory, Peach, Newhoff, and Rubin (1992) investigated attentional processes in aphasic patients in an effort to explore disturbances in attention allocation that may impair communicative and linguistic abilities. Focused attention to auditory information was assessed using event-related potentials (ERPS) while aphasic subjects performed two on-line cognitive tasks. The first task required active attending, with subjects being directed to count the number of times a deviant stimulus was presented via headphones. This measure was then used to assess voluntary attention in aphasic subjects. The second task was designed to measure passive attending which taps automatic attentional mechanisms. During this task, subjects watched an inaudible segment from a familiar movie and were instructed to ignore the tone bursts which were being presented simultaneously. Measures of both active and passive attending were recorded for each of the six test subjects.

Results indicated that automatic attending is preserved in aphasia and that the deficits are in focused attention. More specifically, these researchers found that aphasic subjects focused attention on incoming stimuli much as nonaphasic persons do. In aphasia, however, the attentional resources necessary for completing a discriminative task may be deficient. Therefore, deficits may not be related to the 
engagement of attention, but instead are the result of a reduction in attentional resources which are needed for making discriminative decisions.

A recent study by Tseng, McNeil and Milenkovic (1993) examined the question of how efficiently individuals with aphasia allocate attentional resources in a series of targetdetection tasks. Subjects were required to identify either phonetic targets, semantic targets, or both with all stimuli being presented auditorially via headphones. The two independent variables under investigation included the target occurrence probability and the explicitness of the instruction regarding attention allocation strategies. Results showed that non-brain-damaged subjects were able to use the probability information to reduce their reaction times, indicating an efficient allocational system. In contrast, the reaction times of aphasic subjects remained relatively constant regardless of test condition. These individuals were unable to utilize either of the independent test variables (probability of target occurrence or explicitness of instruction) to foster more efficient allocation of attentional resources. Based on their findings, the authors concluded that aphasic subjects were either impaired in their ability to evaluate task demands for attention or were slower in mobilizing and distributing attentional resources' when compared to non-brain damaged individuals. 
INFERENCE AND READING IN APHASIA

Only a small number of the total messages we receive on a daily basis are explicit in nature. As a result, the receiver of the message is required to fill in the gaps that exist between the actual message and the implied meaning in order to arrive at an appropriate interpretation. This process is referred to as inference and constitutes an integral part of reading comprehension. From a definitional standpoint, inference means going beyond the stated information by using one's existing world knowledge to apprehend the meaning of a text (Farr, Carey, \& Tone, 1986).

Recent studies of inferencing ability in brain damaged populations have centered on those individuals with right hemisphere lesions (Beeman, 1993; Bloise \& Tompkins, 1992; Myers, 1990; Purdy, Belanger \& Liles, 1992; Rau, Kongsbak, Gordon \& Graville, 1992). The vast majority of these studies indicate that right-hemisphere damaged (RHD) patients do, in fact, exhibit marked deficits in their ability to generate inferences. In fact, Myers (1990) states that "Inference failure may represent a "central" deficit underlying most if not all, RHD communication disorders" (p 168).

While evidence of inference failure is relatively well documented in RHD individuals, the literature is somewhat less conclusive with respect to left-hemisphere damaged (LHD) persons. In fact, only a limited number of investigations of inferencing ability have included this 
group of subjects in their experimental design. When LHD subjects are included, it is generally for the purpose of comparing their performance to that of RHD subjects. Nevertheless, such studies do provide an overview of how LHD persons use inference in their decoding of both verbal and written messages.

Stachowiak, Huber, Poeck, and Kershensteiner (1977) were among the first to examine inference in aphasia by measuring aphasic indivduals' performance on tasks requiring contextualization. In this setting, contextualization entailed the use of semantics and pragmatic relations for the purpose of text reconstruction. Their findings indicated that text redundancy greatly enhances the comprehension abilities of aphasic subjects by supplying them with additional cues. In turn, these cues allow for the construction of inferences which ultimately lead to an apprehension of implied meaning. More important, however, was the finding that aphasic performance was not found to be selectively impaired with respect to non-brain-damaged control subjects on these tasks of inferencing ability. From these data, the authors concluded that contextualization skills may be relatively spared in aphasic individuals. Similar findings have been reported by Wilcox, Davis, and Leonard (1978). In their study involving the comprehension of indirect requests by aphasic patients, the ability to grasp implicit or intended meaning was found to be 
relatively well preserved despite an impaired linguistic system.

Unfortunately, the results of subsequent studies are not altogether supportive of this position. In fact, the weight of evidence would appear to suggest that while superior to RHD subjects, LHD patients are impaired in their ability to use inference ( Bihrle, Brownell, \& Powelson, 1986; Myers and Linebaugh, 1984; Myers, Linebaugh, and Mackisack-Morin, 1985). The very definition of aphasia suggests that at least a portion of these deficits may be attributed to linguistic difficulties including problems with syntax, semantics, and phonology. As a result, researchers have constructed a variety of non-verbal inferencing tasks designed to reduce the amount of linguistic loading. Myers and Linebaugh (1984), had their subjects sort inferential picture cards into 3 categories each of which depicted a different emotional state (e.g., despair, play/gaiety, work/dedication, love/affection, mistrust). After each sort, the subjects were asked to explain their groupings using whatever communication modalities were available to them. Within this setting, aphasic individuals demonstrated an impaired ability to use contextual cues relative to control subjects. One possible explanation for this decrease in performance rests in the fact that many of the picture stimuli contained a relatively high degree of irony. As these authors point out, the more 
ironic a picture, the more it serves to contradict immediate associations which, in turn, requires a greater reliance on context for meaning. Such high levels of contextual processing may simply exceed the available capacities in some aphasic persons. Also, the nature of the task may have contributed to the level of error exhibited by the aphasic group. In addition to thematic sorting, subjects were also required to generate the themes which defined the groups. Again, such a task may require a level of analysis and decision making that is particularly problematic for the aphasic subject. In summary, these researchers suggest that there may be a threshold of contextual complexity for aphasic individuals.

In an effort to extend their previous research, Myers, Linebaugh, and Mackisack-Morin (1985) utilized the same experimental design but arranged their card sorts to reflect movement along a continuum between explicit and implicit meaning. Therefore, the first sort consisted of cards requiring little or no inferential ability while the fourth and final sort was comprised of pictures containing highly contextualized features requiring a significant amount of inference. In terms of speed and accuracy, control subjects demonstrated no significant change as they moved from explicit to implicit sorting tasks. Although they experienced more difficulty than non-brain damaged subjects, LHD individuals performed significantly better then RHD 
subjects on sorts three and four.

As in Myers and Linebaugh (1984), subjects were asked to give a rationale for why they felt a group of cards belonged together. These responses were then scored, both according to correctness, and with respect to the level of appreciation for implicit meaning which they contained. Within this context, non-brain damaged subjects demonstrated no difficulty in providing a rationale for their sorting decisions. It is interesting to note that LHD subjects' explanations regarding sorting themes indicated a relatively high level of appreciation for contextual features. In fact, even those responses that were judged as inaccurate or which led to incorrect sorting, reflected an ability to detect commonalty of implicit meaning across pictures. In summary, the findings of this study provide evidence to suggest that LHD subjects are superior to RHD persons in their ability to categorize highly inferential, contextually complex, visual stimuli. It is important to note, however, that these same abilities were found to be impaired in relationship to nonbrain-damaged control subjects.

It is difficult to reconcile these findings with the results of earlier studies in which brain-damaged subjects performed as well as non-brain damaged individuals in tasks which presumably required the use of context for grasping implied meaning (e.g., Stachowiak et al., 1977; wilcox et al., 1978). One possible explanation has been offered by 
Myers \& Linebaugh (1981). These authors have suggested that differences in text redundancy may account for these inconsistent findings. More specifically, they contend that the idioms used by Stachowiak et al. (1977) only elaborated on information or events that were explicitly given earlier in the text. As a result, subjects were not required to draw inferences since the predictive nature of the context itself supplied all of the needed information for selecting the appropriate response. In an effort to examine this hypothesis, Tompkins and Mateer (1984) looked at the effects of text consistency and the nature of judgments required (factual or inferential) on paragraph comprehension between right and left brain-damaged subjects. Stimulus materials for this study consisted of five sets of paired paragraphs which were constructed so that the mood implied by one of the paragraphs was highly positive and the other, highly negative. Subjects were instructed to read the paragraph aloud and then respond to a series of eight, verbally administered, yes/no questions which were either factual or inferential in nature.

The results obtained by these researchers suggest that fundamental differences may exist between the two experimental groups in their ability to use contextual cues for the purpose of apprehending implicit meaning. Interestingly, when stimulus material was highly consistent RHD subjects demonstrated near normal ability in responding 
to yes/no questions, including those which were inferential in nature. In contrast, paragraph consistency appeared to have little effect on the performance of LHD subjects. Regardless of construction, these subjects did more poorly than non-brain-damaged control subjects in responding to inferential questions, while at the same time exhibiting little difficulty with factual items.

With respect to RHD subjects, these findings have been largely supported by more recent studies. For example, Brownell, Potter, Bihrle, \& Gardner (1986) found RHD individuals to be relatively successful in making highly probable inferences based on initial plausible associations. When required to alter their interpretations based on additional information, however, these same subjects experienced considerable difficulty. This process of revising one's interpretation in light of new or conflicting information is known as bridging and is an essential element in narrative comprehension (Bihrle, Brownell, \& Powelson, 1986). Jokes are one form of narrative that rely almost exclusively on this process for achieving their desired outcome and have therefore been used in several studies involving narrative processing. In effect, jokes may be thought of as containing two separate components, coherence and surprise. Coherence is established in the body of the joke and it is here that listeners formulate their initial expectations. The second part of the joke is referred to as 
the punchline and it is at this point that the element of humor is established. In order to be humorous, the punchline must contain an element of incongruity in that it does not conform to the listener's initial expectations. As a result, the listener must make the incongruous punchline fit with the rest of the joke by revising their initial interpretation, thereby establishing coherence (Bihrle, Brownell, \& Powelson, 1986). Studies have shown that RHD persons exhibit a marked reduction in their ability to understand narrative humor (Brownell, Michel, Powelson, \& Gardner, 1983). A follow-up study conducted by Bihrle, Brownell, \& Powelson (1986) provided additional support for this finding. In this experiment, LHD and RHD subjects were compared in their ability to apply surprise and coherence requirements appropriately in two different narrative settings which included jokes and short, non-humorous stories. In the first condition, subjects were read a brief story and supplied with accompanying cartoons which depicted this narrative. They were then asked to select from a field of four choices, the ending which makes the story funny. The same procedure was employed in the second condition except that subjects were required to select the one that ended the story "in an ordinary, not funny way". Foil types for each of these conditions included straight forward, associative non sequitur, neutral non sequitur, and humorous non sequitur. Results showed that LHD persons outperformed 
RHD individuals, making fewer errors in both the joke and story conditions. Of special interest were the respective error patterns which each group exhibited in the joke condition. In this setting RHD subjects demonstrated a distinct preference for endings that were surprising but not coherent. In contrast, LHD patients' errors were characterized by a preference for endings that were coherent but not surprising in nature. These findings indicate that, unlike RHD persons, LHD subjects realize that coherence and bridging are important for understanding and appreciating narrative discourse.

In summary, several inconsistencies may be cited in the literature involving inferencing ability across brain damaged populations. Despite these somewhat contradictory findings, it may be concluded that aphasic persons typically display an impaired ability in making inferences when compared to non-brain damaged individuals. The question of how left and right-hemisphere damaged subjects compare on inference related tasks is beyond the focus of this investigation. The weight of evidence however, would appear to indicate that LHD persons are superior to RHD individuals in their ability to categorize highly inferential, contextually complex visual stimuli.

In contrast, the literature surrounding reading comprehension and aphasia clearly demonstrates that reading skills are impaired in persons with aphasia even though the 
level of severity of reading impairment may differ from one diagnostic group to the next and may correlate with overall level of severity of aphasia. Of more critical importance with respect to the present study is the issue of how LHD and non-brain damaged individuals perform on reading comprehension tasks across inference levels. Those studies which have employed the Nelson Reading Skills Test (NRST) (Hanna, Schell, \& Schreiner, 1977) as a measure of reading comprehension across inference levels have produced conflicting results. In the initial study, conducted by Nicholas and Brookshire (1987), aphasic and non-brain damaged subjects demonstrated the same error pattern, making more errors on test items requiring high levels of inference and fewer errors on literal items. In subsequent studies by Graville \& Rau, (1990) and Rau et al. (1992) this error pattern was not found to exist.

The diversion of attentional resources away from test stimuli as a result of having subjects read test material aloud has been offered as one possible explanation for this discrepancy in findings. Research in the area of attention and aphasia indicates that aphasic persons do experience difficulty in attending skills. The weight of evidence, however, suggests that these deficits are not attributable to a reduction in attentional resources. Instead, aphasic individuals appear to be impaired in their ability to allocate or focus their attentional resources in an 
efficient manner with respect to the task at hand.

Through the use of the Nelson Reading Skills Test and by controlling the method whereby subjects read test materials, the present study investigated whether or not reading method influences subject performance across levels of inference. Should reading method be shown to affect test performance, it may be inferred that reading aloud does in fact, alter the allocation of attentional resources. 
METHODS AND PROCEDURES

\section{SUBJECTS}

Two groups of subjects were recuited for this study. The experimental group consisted of 15 individuals who had been diagnosed with aphasia resulting from a single, left hemisphere cerebrovascular accident (CVA). The mean age for experimental group subjects was 59.67 years (range 44-71 years). These individuals were all recruited from a large VA medical center, were at least four months post-onset of their CVA and were native English speakers. Additional requirements for inclusion were: adequate vision to read large print; premorbid reading skill at or above the seventh-grade level as determined by level of education, occupation, and subject's own report; a minimum score of 10.0 on each item of Subtest VII (a reading comprehension task) of the Porch Index of Communicative Ability, (PICA) (Porch, 1967); and a mean score at or above the 60th percentile on the short form of the PICA (SPICA) (DiSimoni, Reith, \& Darley, 1980). These inclusion criteria are consistent with those employed in earlier studies (Graville \& Rau, 1990; Rau et al., 1992; and Nicholas \& Brookshire, 1987) and are designed to screen out those individuals with moderate to severe language impairments. Descriptive characteristics for the inclusion criteria may be found in Table 1 . 
TABLE 1

DESCRIPTIVE CHARACTERISTICS OF LEFT BRAIN DAMAGED (LHD) SUBJECTS

\begin{tabular}{|c|c|c|c|c|}
\hline Subject & Age & Education & Time post-CVA & $\begin{array}{c}\overline{\mathrm{X}} \\
\text { SPICA } \\
\text { Score }\end{array}$ \\
\hline $\begin{array}{l}1 \\
2 \\
3 \\
4 \\
5 \\
6 \\
7 \\
8 \\
9 \\
10 \\
11 \\
12 \\
13 \\
14 \\
15\end{array}$ & $\begin{array}{l}72 \\
46 \\
60 \\
57 \\
65 \\
71 \\
53 \\
61 \\
65 \\
65 \\
71 \\
61 \\
54 \\
44 \\
50\end{array}$ & $\begin{array}{l}12 \\
14 \\
13 \\
20 \\
12 \\
13 \\
10 \\
14 \\
17 \\
12 \\
12 \\
18 \\
14 \\
16 \\
16\end{array}$ & $\begin{array}{r}103 \\
219 \\
62 \\
182 \\
86 \\
185 \\
79 \\
14 \\
74 \\
92 \\
29 \\
82 \\
43 \\
28 \\
105\end{array}$ & $\begin{array}{l}12.40 \\
13.58 \\
11.75 \\
12.00 \\
13.85 \\
13.90 \\
13.60 \\
13.25 \\
12.45 \\
12.80 \\
12.10 \\
13.33 \\
12.10 \\
12.30 \\
13.20\end{array}$ \\
\hline $\begin{array}{l}\text { Mean } \\
\text { SD* }^{\star}\end{array}$ & $\begin{array}{r}59.67 \\
8.89\end{array}$ & $\begin{array}{r}14.2 \\
2.7\end{array}$ & $\begin{array}{l}92.2 \\
60.5\end{array}$ & $\begin{array}{r}12.84 \\
.729\end{array}$ \\
\hline
\end{tabular}

*SD $=$ Standard Deviation 
The control group consisted of 15 non-brain damaged (NBD) individuals with no history of neurological impairment and were drawn from the greater vancouver, washington area. Mean age for this group was 69.60 years (range 58-79 years). Additional requirements for the control group included: adequate visual acuity to read large print; reading level at, or above the seventh-grade level; native English speaker. Descriptive characteristics for the non-brain damaged group may be found in Table 2 .

Individuals from the experimental (Aphasic) group who met the requirements for inclusion were randomly assigned to either the "left brain damaged (LHD) oral reading" or the "left brain damaged (LHD) silent reading" subgroup. Descriptive characteristics of these two left-hemisphere damaged subgroups may be found in Table 3. NBD subjects were randomly assigned to either the "non-brain damaged (NBD) oral reading" or the "non-brain-damaged (NBD) silent reading subgroup. Descriptive statistics for these two non-brain damaged subgroups may be found in Table 4.

\section{HUMAN SUBJECT PROCEDURES}

Approval for the use of human subjects in this study was obtained from the Human Subjects Research Review Committee of Portland State University and from the subcommittee on Human Studies of the Portland Veterans Affairs Medical Center 
TABLE 2

DESCRIPTIVE CHARACTERISTICS OF NON BRAIN DAMAGED (NBD) SUBJECTS

\begin{tabular}{lcc} 
Subject & $\begin{array}{c}\text { Age } \\
\text { (yrs) }\end{array}$ & $\begin{array}{c}\text { Education } \\
\text { (yrs) }\end{array}$ \\
\hline 1 & & \\
2 & 66 & 16 \\
3 & 74 & 14 \\
4 & 60 & 16 \\
5 & 67 & 16 \\
6 & 72 & 18 \\
7 & 74 & 12 \\
8 & 79 & 12 \\
9 & 67 & 13 \\
10 & 72 & 12 \\
11 & 74 & 13 \\
12 & 73 & 16 \\
13 & 58 & 12 \\
14 & 66 & 13.8 \\
15 & 70 & 2.178 \\
\hline Mean & 71 & \\
SD* & 69.53 & \\
\hline
\end{tabular}

${ }^{\star} \mathrm{SD}=$ Standard Deviation 
TABLE 3

COMPARISON OF DESCRIPTIVE CHARACTERISTICS FOR LHD SUBGROUPS

\begin{tabular}{|c|c|c|c|c|c|}
\hline GROUP & MEASURE & AGE & TIME POST & EDUCATION & SPICA \\
\hline $\begin{array}{l}\text { LHD } \\
\text { ORAL } \\
\text { READING } \\
\mathrm{N}=7\end{array}$ & $\begin{array}{c}\bar{X} \\
\text { SD } \\
\text { RANGE }\end{array}$ & $\begin{array}{r}60.57 \\
9.50 \\
46-72\end{array}$ & $\begin{array}{r}130.7 \\
62.4 \\
62-218\end{array}$ & $\begin{array}{r}13.43 \\
3.15 \\
10-20\end{array}$ & $\begin{array}{r}13.01 \\
.92 \\
11.75-13.9\end{array}$ \\
\hline $\begin{array}{l}\text { LHD } \\
\text { SILENT } \\
\text { READING } \\
\mathrm{N}=8\end{array}$ & $\begin{array}{c}\overline{\mathrm{x}} \\
\text { SD } \\
\text { RANGE }\end{array}$ & $\begin{array}{r}58.87 \\
8.90 \\
44-71\end{array}$ & $\begin{array}{l}58.4 \\
34.0 \\
14-105\end{array}$ & $\begin{array}{r}14.875 \\
2.232 \\
12-18\end{array}$ & $\begin{array}{c}12.69 \\
.521 \\
12.1-13.33\end{array}$ \\
\hline$\overline{\mathrm{X}}=$ MEAN & SD & $=$ stand & deviation & & \\
\hline
\end{tabular}


TABLE 4

SUMMARY OF DESCRIPTIVE STATISTICS FOR NBD SUBGROUPS

\begin{tabular}{|c|c|c|c|}
\hline Group & Measure & $\begin{array}{c}\text { Age } \\
\text { (yrs) }\end{array}$ & $\begin{array}{c}\text { Educational Level } \\
\text { (yrs) }\end{array}$ \\
\hline $\begin{array}{l}\text { NBD } \\
\text { Oral } \\
\text { Reading } \\
\mathrm{N}=8\end{array}$ & $\begin{array}{c}\bar{X} \\
S D \\
\text { range }\end{array}$ & $\begin{array}{r}69.87 \\
5.99 \\
60-79\end{array}$ & $\begin{array}{r}14.750 \\
2.121 \\
12-18\end{array}$ \\
\hline $\begin{array}{l}\text { NBD } \\
\text { Silent } \\
\text { Reading } \\
\mathrm{N}=7\end{array}$ & $\begin{array}{c}\bar{X} \\
\text { SD } \\
\text { range }\end{array}$ & $\begin{array}{r}69.29 \\
5.22 \\
58-74\end{array}$ & $\begin{array}{r}14.000 \\
3.560 \\
10-21\end{array}$ \\
\hline $\overrightarrow{\mathrm{X}}=\mathrm{MEAN}$ & & $\mathrm{SD}=\mathrm{STANDARD}$ & DEVIATION \\
\hline
\end{tabular}


(Appendix A). Following an explanation of the nature and purpose of the study, all subjects were asked to sign an informed consent form indicating that they understood their role as participants in the study (Appendix B). Subjects were also advised that they could withdraw from the study at any time, without penalty or loss of VA benefits. Group homogeneity

A series of $t$-tests were performed to determine whether the two experimental subgroups differed significantly on the variables of age, time post oneset, educational level, and SPICA score. No significant difference was found between groups for age, educational level or SPICA scores. A significant difference was found between subjects with regard to time post onset of CVA $(p<.023)$. These results may be found in Table 5 .

A series of t-tests were also conducted in order to determine whether or not differences existed between the two control groups with respect to age and educational level. No significant difference was found for either of these two variables. Results are displayed in Table 6 .

Differences between experimental and control group subjects were also investigated using a series of t-tests. No significant difference was found to exist on the basis of educational level; however, a significant difference was found to exist between groups with respect to age $(p<.001)$. Results are displayed in Table 7. 
TABLE 5

SUMMARY OF $t$-TESTS FOR INDEPENDENT MEANS FOR AGE, EDUCATION, TIME POST CVA, AND SPICA (LHD SUBGROUPS)

\begin{tabular}{|c|c|c|c|c|c|}
\hline & $\begin{array}{l}\text { Overall } \\
\text { mean }\end{array}$ & SD & $\begin{array}{l}\text { pooled within } \\
\text { groups SD }\end{array}$ & $t$ & $\mathrm{p}$ \\
\hline AGE & 59.67 & 8.89 & 9.184 & -.36 & .73 \\
\hline EDUCATION & 14.2 & 2.704 & 2.697 & 1.01 & .34 \\
\hline $\begin{array}{l}\text { TIME } \\
\text { POST CVA }\end{array}$ & 92.1 & 60.4 & 49.19 & -2.73 & $.023 *$ \\
\hline SPICA & 12.841 & .729 & .737 & -.81 & .44 \\
\hline $\begin{array}{l}\text { SD }=\text { Standard d } \\
t=\text { t-Statisti } \\
\mathrm{P}=\text { Pobability } \\
\star=\text { Significant }\end{array}$ & $\begin{array}{l}\text { leviation } \\
(P<.05)\end{array}$ & & & & \\
\hline
\end{tabular}


TABLE 6

SUMMARY OF $t$-TESTS FOR INDEPENDENT MEANS FOR AGE AND EDUCATION (NBD SUBGROUPS)

Overall SD pooled within $t \quad p$ mean groups SD

$\begin{array}{llrrrr}\text { AGE } & 69.60 & 5.45 & 5.645 & .20 & .84 \\ \text { EDUCATION } & 14.4 & 2.798 & 2.876 & .49 & .64\end{array}$

$\mathrm{SD}=$ Standard deviation

$t=t$-Statistic

$P=$ Probabiltiy

* = Significant $(P<.05)$ 
TABLE 7

SUMMARY OF $t$-TESTS FOR INDEPENDENT MEANS FOR AGE AND EDUCATION (NBD AND LHD GROUPS)

Overall SD pooled within $t \quad p$ mean groups SD

AGE

$64.60 \quad 8.86$

8.430

$-3.64 .001 *$

EDUCATION

14.0

2.42

2.455

$.45 \quad .32$

$S D=$ Standard deviation

$t=$ t-statistic

$\mathrm{p}=$ Probability

* = Significant $(\mathrm{P}<.05)$ 
TESTING INSTRUMENTS

The Porch Index of Communicative Ability (PICA) (Porch, 1967) consisting of 18 subtests, is designed to assess the general communicative ability or communicative efficiency of individuals with aphasia. A total of seven different modalities including writing, copying, gesturing, speaking, auditory comprehension, visual perceptual ability and reading are evaluated. The PICA provides percentile scores for each subtest which, in turn, may be used to construct an overall score, percentile score, and severity rating for the testee.

The SPICA, (DiSimoni, Keith, \& Darley, 1980) consisting of only four subtests, represents a shortened version of the PICA. Although significantly shorter in length, the SPICA was found to predict overall PICA scores accurately at the $\mathrm{R}=$ 0.98 level (DiSimoni, Keith, \& Holt, 1975). The modalities through which the SPICA establishes an overall communicative efficiency rating are verbal, auditory, reading and writing. While providing less in-depth information than the PICA, the SPICA has been shown to be a useful tool for screening purposes (Holtzapple, Pohlman, LaPointe \& Graham, 1989). Given these findings, the SPICA was chosen to serve as a screening device in this study to assess the overall communicative efficiency of the experimental group subjects. 
A sample copy of the SPICA test form may be found in Appendix C.

The Nelson Reading Skills Test (NRST) (Hanna, Schell, \& Schreiner, 1977), Form 4 of Level B constituted the dependent variable in the present study and was employed to assess subjects' reading comprehension and reading inferencing ability. Form 4, Level B consists of five paragraphs each with between five and eight multiple choice questions to be answered. A total of 33 questions examine reading comprehension across 3 levels of inference. The breakdown is as follows: 11 questions require a high level of inference, denoted as "high inference;" 12 questions requiring a moderate level of inference ability are designated "translational;" the remaining 10 questions may be answered directly from the passage and are denoted as "literal."

Each passage was presented separately on a single, 8 $1 / 2 " \times 11 "$ sheet of paper with all text being double spaced. These stimuli are the same as those employed by Rau and Graville (1990) and Rau et al. (1992). A sample paragraph and associated test questions may be found in Appendix D.

\section{Experimental Procedures}

Subjects assigned to the "left-hemisphere damaged oral reading" and "non-brain damaged oral reading" subgroups were instructed to read both the passages and questions aloud and 
to indicate the correct answer from the four choices presented.

Subjects assigned to the "left-hemisphere damaged silent reading" and "non-brain damaged silent reading" subgroups were instructed to read each of the passages and corresponding questions in a silent manner and to indicate their choice of answers.

Subjects were allowed to reread the passage and set of applicable questions if they so chose. A standardized set of instructions describing the exact procedure and method of reading was read to each subject. Appendix E contains a copy of these instructions.

Responses were recorded on-line by the examiner who recorded the subject's response by marking down the corresponding letter on the answer sheet. The examiner's score sheet also contained a letter beside each question corresponding to the level of inference which that particular question required. The letter (I) was used to signify literal questions, (H) denoted high level inference questions and $(T)$ represented moderate level or translational questions. A sample score sheet is displayed in Appendix F. Administration time for the NRST ranged from 11 to 49 minutes; however, subjects were allowed as much time as needed to complete the test.

MEASUREMENTS AND DATA ANALYSIS SYSTAT (Wilkinson, 1986), a software program for 
statistical analysis was used to perform all statistical computations in this study.

Descriptive statistics were used to calculate raw score and percentage correct score for each subject, mean percentage correct scores and standard deviations for each group for the three levels of inference.

A repeated measures ANOVA (Wilkerson, 1986) was employed to determine whether or not a significant difference in performance existed within the groups across the three inference levels. Due to the fact that there are an unequal number of questions at each inference level, raw scores for each type of question were converted to percent correct scores before performing the ANOVA computation. The level of significance chosen for this study was, $\mathrm{p}<.05$. 


\section{RESULTS AND DISCUSSION}

\section{RESULTS}

Results of the present study were analyzed through the use of descriptive statistics, t-tests and a series of oneway repeated measures analysis of variance (ANOVA).

\section{Review of the Research Question}

1) Will left-hemisphere damaged and non-brain damaged subjects commit significantly more errors on the Nelson Reading Skills Test when reading aloud or when reading silently?

2) Will left-hemisphere damaged and non-brain damaged subjects commit significantly more errors on high inference level questions as compared to low inference level questions when reading aloud or when reading silently?

\section{Descriptive Results}

Table 8 contains the means, standard deviations, and ranges of NRST scores and total scores per question type for both experimental subgroups. Table 9 contains the same descriptive information for the oral and silent reading control groups. 
TABLE 8

SUMMARY OF DESCRIPTIVE STATISTICS FOR EXPERIMENTAL SUBJECTS NRS'T SCORES

\begin{tabular}{|c|c|c|c|c|c|}
\hline GROUP & MEASURE & $\begin{array}{l}\text { LITERAL } \\
\text { SCORE }\end{array}$ & $\begin{array}{l}\text { TRANSLATIONAL } \\
\text { SCORE }\end{array}$ & $\begin{array}{l}\text { HIGH } \\
\text { SCORE }\end{array}$ & $\begin{array}{l}\text { TOTAL } \\
\text { SCORE }\end{array}$ \\
\hline $\begin{array}{l}\text { LHD } \\
\text { ORAL } \\
\text { READING } \\
\mathbf{N}=7\end{array}$ & $\begin{array}{l}\bar{X} \\
\text { SD } \\
\text { range }\end{array}$ & $\begin{array}{l}6.429 \\
2.149 \\
3-9\end{array}$ & $\begin{array}{l}8.286 \\
2.215 \\
4-10\end{array}$ & $\begin{array}{l}7.143 \\
2.478 \\
4-10\end{array}$ & $\begin{array}{r}21.86 \\
2.26 \\
13-29\end{array}$ \\
\hline $\begin{array}{l}\text { LHD } \\
\text { SILENT } \\
\text { READING } \\
\mathrm{N}=8\end{array}$ & $\begin{array}{l}\bar{X} \\
\text { SD } \\
\text { range }\end{array}$ & $\begin{array}{l}6.75 \\
1.832 \\
4-9\end{array}$ & $\begin{array}{l}8.375 \\
2.615 \\
3-11\end{array}$ & $\begin{array}{l}8.125 \\
1.727 \\
6-11\end{array}$ & $\begin{array}{r}23.25 \\
5.23 \\
16-30\end{array}$ \\
\hline
\end{tabular}

$\overline{\mathrm{X}}=$ Mean

$\mathrm{SD}=$ Standard Deviation 
TABLE 9

SUMMARY OF DESCRIPTIVE STATISTICS FOR CONTROL GROUP NRST SCORES

GROUP

MEASURE

LITERAI

TRANSLATIONAL

SCORE

HIGH TOTAL SCORE

SCORE SCORE

$\begin{array}{llllrr}\text { NBD } & \bar{X} & 9.125 & 10.75 & 10.143 & 30.125 \\ \text { ORAL } & \text { SD } & 1.126 & 1.035 & .886 & 2.416 \\ \begin{array}{l}\text { READING } \\ \text { N }=8\end{array} & \text { range } & 7-10 & 9-12 & 9-11 & 25-32 \\ & & & & & \\ \text { NBD } & \bar{X} & & & 10.250 & 29.29 \\ \text { SILENT } & \text { SD } & 1.143 & 10.714 & .886 & 3.40 \\ \text { READING } & \text { range } & 7-10 & 2.138 & 9-11 & 22-33 \\ N=7 & & & 9-12 & & \end{array}$

$\overline{\mathrm{x}}=$ Mean $\mathrm{SD}=$ Standard Deviation $\quad \mathrm{NBD}=$ Non-brain damaged 
ANOVA Results

An ANOVA with repeated measures (Wilkerson, 1986) was performed in order to examine whether or not a significant difference existed, both between and within groups, with respect to question type. In order to analyze this question, the interaction of three factors was considered. These included, group distinction (either control or experimental) designated as factor ' $A$ ', the method of reading (either silent or aloud, represented as 'B', and question level (low, translational, or high) referred to as 'level'. A significant difference was found to exist between the performance of control group and experimental group subjects $(p=<.000 ; d f=1)$. With respect to reading type, there was no significant difference in performance between those subjects who read test materials aloud and those who read in a silent manner $(p=.883 ; d f=1)$. In addition, no significant interaction was detected between group type (control and experimental) and question type $(\mathrm{p}=.477 ; \mathrm{df}=$ 1).

The within subjects analysis revealed no significant difference in mean scores for each of the three question types (high, translational and low) $(\mathrm{p}=.134 ; \mathrm{df}=2)$. The interaction of question type and group type also produced no significant findings, indicating that the pattern of responses of the control group was not significantly different from the pattern displayed by the experimental 
group $(p=.656 ; \mathrm{df}=2)$. The purpose of the present study was to determine whether or not the method of reading had a significant impact on test scores across levels of inference. The within subjects portion of the repeated measure analysis of variance (ANOVA) revealed no significant difference in the pattern of scores across inference levels between the oral and silent reading groups $(p=.299 ; \mathrm{df}=2)$. Finally, no significant difference was found with respect to the pattern of scores across the four different groups (control aloud, control silent, experimental aloud, experimental silent) $(\mathrm{p}=$ $.554 ; \mathrm{df}=2)$. The pattern of scores for each of these groups may be viewed in Figure 1 while Table 10 contains the results of the ANOVA.

\section{DISCUSSION}

As previously mentioned, three studies have thus far been conducted in an effort to assess the validity of the Nelson Reading skills Test as a tool for measuring reading comprehension across inference levels. The present study was designed to assess if the method whereby subjects read test materials would impact subject performance and might thus be responsible for the differences in findings reported in previous studies.

Comparing the results of the present study and those obtained by Nicholas and Brookshire (1987) one finds few similarities, save for the fact that in both studies the control group's scores were significantly better then those 


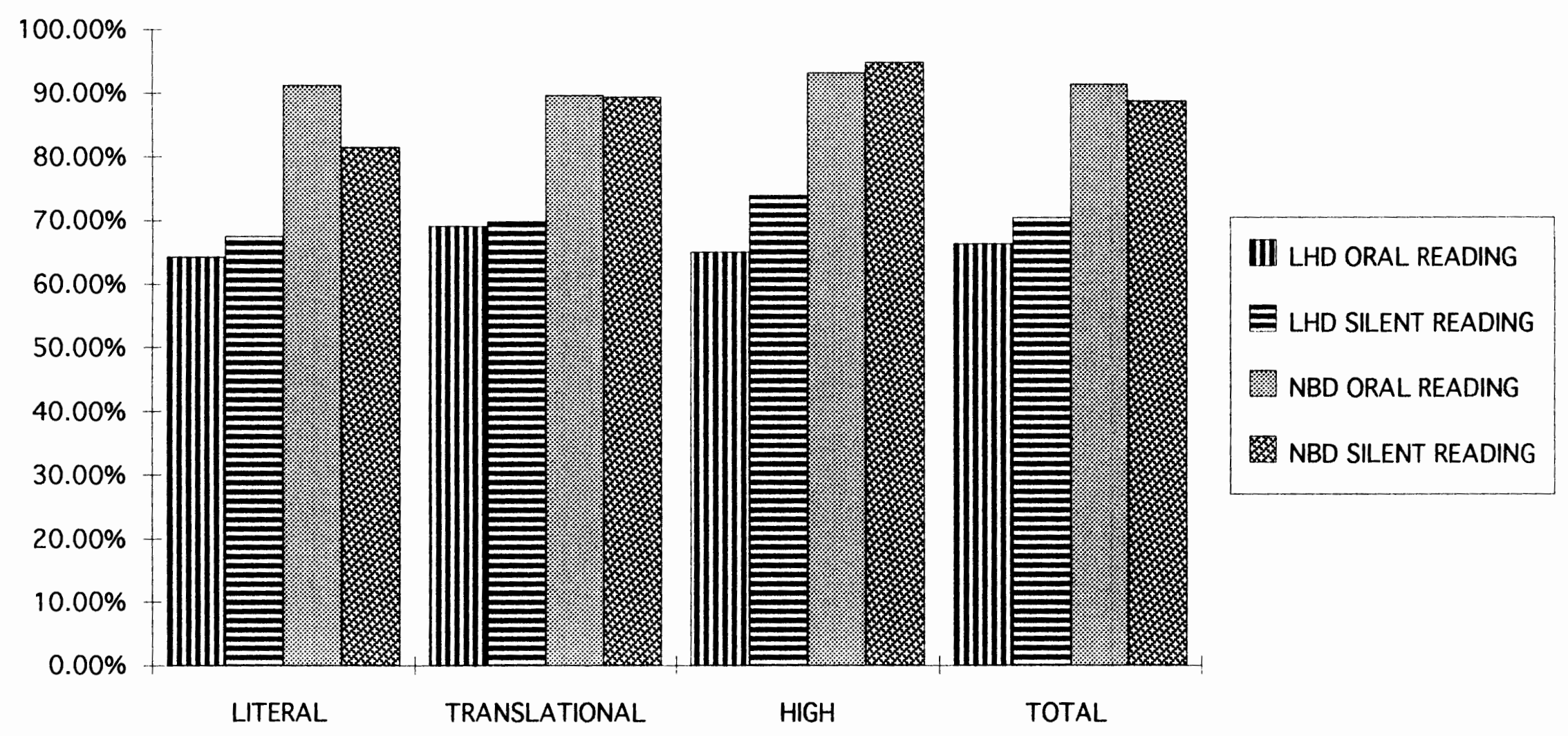

FIGURE 1. Mean percentage correct scores for LHD and NBD subjects on test items of the NRST by levels of inference 
TABLE 10

SUMMARY OF THE ANALYSIS OF VARIANCE WITH REPEATED MEASURES

BY QUESTION TYPE WITHIN AND BETWEEN GROUPS

BETWEEN SUBJECTS

SOURCE

SS

$\mathrm{DF}$

MS

$\mathbf{F}$

P

$\begin{array}{lrrrrr}\text { A } & 10533.850 & 1 & 10533.850 & 19.271 & .000 * \\ \text { B } & 12.022 & 1 & 12.022 & .022 & .883 \\ \text { A/B } & 284.558 & 1 & 284.558 & .0521 & .477 \\ \text { ERROR } & 14211.934 & 26 & 546.613 & & \end{array}$

WITHIN SUBJECTS

SOURCE

SS

DF

MS

F

P

\begin{tabular}{lccccc}
\hline LEVEL & 470.603 & 2 & 235.302 & 2.094 & .134 \\
LEVEL/A & 95.376 & 2 & 47.688 & .424 & .656 \\
LEVEL/B & 277.755 & 2 & 138.877 & 1.236 & .299 \\
LEVEL/A/B & 134.346 & 2 & 67.173 & .598 & .544 \\
ERROR & 5844.115 & 52 & 112.387 & & \\
& & & & \\
\hline
\end{tabular}


of the experimental group. The research reviewed earlier clearly demonstrated that individuals with aphasia are impaired in their ability to read and comprehend paragraph length material. Therefore, the fact that this outcome was observed in both studies would tend to suggest that the Nelson Reading Skills Test (NRST) does measure reading comprehension at some level. The present study does not, however, support Nicholas and Brookshire's (1987) conclusion that the NRST is capable of measuring reading comprehension across inference levels. As previously mentioned, Nicholas and Brookshire's subjects made significantly more errors on high inference level questions then those requiring low levels of inference. Neither the control nor experimental subject groups in the present study demonstrated this pattern of error regardless of whether they read test materials aloud or silently. It is interesting to note that for all groups, regardless of reading style, the mean scores for high level questions are greater then mean scores for low level questions. This finding would appear to call into question whether or not, for adult readers, high level questions are more difficult to answer then those designated as low level inference questions. A basic premise in all previous experiments involving the NRST has been that high inference level questions are more difficult then low inference level questions. It would therefore appear unlikely that both experimental and control groups in this study would find high 
inference level questions to be less difficult.

One possible explanation for this outcome may involve the level or mode of text processing used by test subjects. Van Dijk and Kintsch (1983) have proposed a model whereby text comprehension is divided into two modes, microprocessing and macroprocessing. Microprocessing involves the handling of individual propositions as conveyed by various syntactic and stylistic devices including changes in word order, paraphrases, repetitions and coreference relations (Huber, 1990). In contrast, macroprocessing focuses on that part of the text base that represents the main ideas, often referred to as theme, gist, topic or upshot (Mross, 1990). In addition, general world knowledge and pragmatic reasoning play a crucial role for macroprocessing (Huber, 1990). Given the fact that microprocessing requires an extensive amount of linguistic processing, it is not surprising that studies have shown that individuals with aphasia tend to rely on macroprocessing for text comprehension (Huber and Gleber, 1982). The same pattern of increased reliance on macroprocessing was also exhibited by non-brain damaged subjects when confronted with redundant, longer, and more complex textual information (Stachowiak, Huber, Poeck, and Kerschensteiner, 1977).

The nature of macroprocessing and the extent to which it is used in text comprehension may be particularly relevant for interpreting subject performance on the high inference 
level questions found in the NRST. First of all, obtaining the correct answer on several of these high level test items entails being able to identify and comprehend the overall topic contained in that particular selection. Through the use of macroprocessing skills, subjects may have been able to correctly ascertain the gist or theme of the paragraph. and then select the appropriate answer by relying upon this information along with their general knowledge and pragmatic reasoning skills (For examples, see questions 1,3,6,12,19, and 33 in Appendix D). In other words, a few of the "high level" test items may, in fact, be tapping macroprocessing skills rather then assessing the subject's ability to use high level inferencing skills. Conversely, supplying the correct answer to some literal and translational questions may have required a substantial amount of microprocessing skill and were therefore, more difficult, particularly for experimental group subjects.

This interpretation of test findings, based on the mode of text comprehension, constitutes one possible explanation for results obtained in the present study. It is possible that other factors are responsible for the discrepancy which exists between the results of this study and those of Nicholas and Brookshire (1987) with respect to the NRST and its ability to measure reading comprehension across inference levels. The results of the present study do however, indicate that reading method does not significantly 
affect subject performance on the NRST. 


\section{CHAPTER V}

\section{SUMMARY AND IMPLICATIONS}

\section{SUMMARY}

The purpose of this study was to determine whether or not the method of reading (either silently or aloud) significantly influenced subject performance across levels of inference using the Nelson Reading Skills Test (NRST). The experimental group was comprised of 15 subjects who had suffered a CVA to the left hemisphere of the brain. A control group comprised of 15 subjects with no known brain damage was also tested. Both experimental and control groups were divided into two subgroups with subjects being randomly assigned to either a reading aloud or silent reading group. Experimental subjects were selected after they had demonstrated an adequate level of linguistic functioning, as measured by the SPICA (a test instrument which measures communicative efficiency), to perform the experimental tasks. All subjects were administered the Nelson Reading Skills Test. Test questions on the NRST are grouped into three categories corresponding to literal, translational, and high levels of inference. Subjects were presented with a total of five passages. Following each passage, subjects were asked to answer a series of questions about that passage and to indicate their response by pointing to the correct answer from a field of four choices. All subjects were informed 
that they could refer back to the passage whenever needed in order to answer the questions.

Results revealed total NRST performance to be significantly better for non-brain damaged subjects. No significant difference in performance was found to exist in either the control or experimental groups with respect to reading method. In addition, neither reading method produced the error pattern described by Nicholas and Brookshire (1987) in which subjects made more errors on high inference level questions then on literal level test items. The results of this study confirm the findings of Rau and Graville (1990) and Rau et al. (1992) thereby adding additional evidence to suggest that the Nelson Reading Skills Test is not sensitive enough to measure reading comprehension of aphasic adults across inference levels.

\section{CLINICAL IMPLICATIONS}

The fact that the non-brain damaged subjects significantly outperformed the left-hemisphere damaged individuals suggests that the NRST does differentiate between these two groups with respect to reading comprehension skill. In addition, the NRST has also been shown to have a high level of passage dependency. These two factors indicate that the NRST may be superior to other measures in assessing reading comprehension within this population. While the NRST may be a useful tool for assessing general reading comprehension, it does not 
appear to be well suited for detecting differences in performance across inference levels.

The primary clinical question addressed in this study is one of methodology. More specifically, does reading method affect subject performance on tasks involving reading comprehension. Results would appear to indicate that this variable has little effect on overall performance. In light of these findings, perhaps the decision whether to read test materials aloud or silently should be made on a case by case basis or even left up to the individual being tested. This is, of course, providing that the test protocol does not stipulate how materials are to be read.

\section{IMPLICATIONS FOR FURTHER RESEARCH}

The findings of this study provide additional support for the conclusions reached by Graville and Rau (1990) and Rau et al. (1992). In both of these previous studies it was found that the NRST was not a useful tool for assessing reading comprehension across inference levels in brain damaged adults. Future research efforts should therefore be directed toward finding an instrument that is capable of assessing inferential reading abilities in persons with brain damage. Follow-up studies are also needed to further examine if reading methodology (oral or silent) does in fact impact the reading comprehension performance of brain-damaged individuals using other standardized reading assessments. 
REFERENCES

Beeman, M. (1993). Semantic processing in the right hemisphere may contribute to drawing inferences from discourse. Brain and Language, 44, 80-120.

Bihrle, A.M., Brownell, H.H., \& Powelson, J.A. (1986). Comprehension of humorous and nonhumorous materials by left and right brain-damaged patients. Brain and Cognition, $5,399-411$.

Bloise, C.G.R., Tompkins, C.A. (1992). Right brain damage and inference revision revisited. In T. Prescott (ed.) Clinical aphasiology, (Vol. 21, pp. 145-153). Austin, TX: Pro-Ed.

Brookshire, R.H. (1992). An introduction to neurogenic communication disorders (4th ed.). St. Louis: Mosby Year.

Brownell, H.H., Michel, D., Powelson, J.A., \& Gardner, H. (1983). Surprise but not coherence: Sensitivity to verbal humor in right-hemisphere patients. Brain and Language, 18, 20-27.

Brownell, H.H., Potter, H.H., Bihrle, A.M., \& Gardner, H. (1986). Inference deficits in right brain-damaged patients. Brain and Language, 27, 310-321.

Disimoni, F., Keith, R., \& Darley, F. (1980). Predication of PICA overall score by short versions of the test. Journal of Speech and Hearing Research, 23, 511-516.

Disimoni, F., Reith, R., \& Holt, D. L. (1975). Practicality of shortening the Porch index of communicative ability. Journal of Speech and Hearing Research, 18, 491-497.

Eisenson, J. (1954). Examining for aphasia. New York: The Psychological Corporation.

Farr, R., Carey, R., \& Tone, B. (1986). Recent theory and research into the reading process: Implications for reading assessment. In Judith Orasnau (ED.), Reading comprehension from research to practice (pp.135-150). Hillsdale, NJ: Lawrence Erlbaum Associates.

Gardner, H. \& Zurif, E. (1976). Critical reading of words and phrases. Brain and Language, 3, 173-190. 
Goodglass, H., \& Kaplan, E. (1983). Assessment of aphasia and related disorders. Philadelphia: Lea \& Febiger.

Graville, D.J., \& Rau, M. T. (1990). Reading comprehension of directly stated and inferred information in paragraph-length material by nondemented and demented elderly subjects. In T. Prescott (ed.) Clinical aphasiology, (Vol. 20, pp. 77-86). Austin, Tx: ProEd.

Hanna, G., Schell., \& Schreiner, R. (1977). The Nelson Reading Skills Test. Chicago: Riverside Publishing.

Holtzapple, P., Pohlman, K., LaPointe, L. \& Fletcher Graham, L. $(1989)$. Does the SPICA mean PICA? In T. Prescott (Ed.) Clinical aphasiology, (Vol. 18, pp. 131-144). Austin, TX: Pro-Ed.

Huber, W. (1990). Text comprehension and production in aphasia: analysis in terms of micro-and macroprocessing. In Joanette, $\mathrm{Y}$., \& Brownell, H. H. (Ed.) Discourse ability and brain damage. New York: Springer-Verlag.

Huber, W., \& Gleber, J. (1982). Linguistic and nonlinguistic processing of narratives in aphasia. Brain and Language, 16: 1-18.

Kahneman, D. (1973). Attention and Effort. Englewood Cliffs, NJ: Prentice-Hall.

Kertesz, A. (1979). Aphasia and associated disorders. New York: Grune and Stratton.

Kertesz, A. (1982) - The Western Aphasia Battery. New York: Grune \& Stratton.

Kongsbak, U. (1990) - Reading comprehension of literal, translational, and high inference level questions in aphasic and right hemisphere damaged adults. Master's thesis. Portland State University, Portland, OR.

LaBerge, P., \& Samuels, S.J. (1974). Toward a theory of automatic information processing in reading. Cognitive Psychology, 6: 293-323.

LaPointe, L.L., \& Horner, J. (1979). The Reading Comprehension Battery for Aphasia. Tigard, OR: C.C. Publications. 
McNeil, M.R. (1983). Aphasia: Neurological considerations. Topics in Language Disorders, 3(4), 1-19.

McNeil, M. R. (1991). Toward the integration of resource allocation into a general theory of aphasia. In T. Prescott (ed.) Clinical aphasiology, (Vol. 20, pp. 2138). Austin, Tx: Pro-Ed.

Mross, E. F. (1990). Text analysis: macro-and microstructural aspects of discourse processing. In Joanette, Y., \& Brownell, H. H.(Ed.) Discourse ability and brain damage. New York: Springer-Verlag.

Myers, P.S., \& Linebaugh, C.W. (1981). Comprehension of idiomatic expressions by right-hemisphere-damaged adults. In R.H. Brookshire (Ed.), Clinical aphasiology: Conference Proceedings. Minneapolis, MN: BRK Publishers.

Myers, P.S., \& Linebaugh, C.W. (1984). The use of contextdependent pictures in aphasia rehabilitation. In R.H. Brookshire (Ed.), Clinical aphasiology (Vol. 14, pp. 145-152). Minneapolis, MN: BRK Publishers.

Myers, P.S., Linebaugh, C.W., \& Mackisack-Morin, E.L. (1985). Extracting implicit meaning: Right versus left hemisphere damage. In R.H. Brookshire (Ed.), Clinical aphasiology (Vol. 15, pp.72-82). Minneapolis, MN: BRK Publishers.

Myers, P.S. (1990). Inference failure: the underlying impairment in right-hemisphere communication disorders. In T. Prescott (ed.) Clinical aphasiology, (Vol. 20, pp. 167-180). Austin, Tx: Pro-Ed.

Nicholas, L.E., MacLennan, D.L., \& Brookshire, R.H. (1986). validity of multiple-sentence reading comprehension tests for aphasic adults. Journal of Speech and Hearing Disorders, 51, 82-87.

Nicholas, L. E., \& Brookshire, R. H., (1987). Error analysis and passage dependency of test items from a standardized test of multiple-sentence reading comprehension for aphasics and non-brain-damaged adults. Journal of Speech and Hearing Disorders, 52 , 358-366. 
Peach, R. K. , Newhoff, M. , \& Rubin, S. S. (1992). Attention in aphasia as revealed by event-related potentials: A preliminary investigation. In $T$. Prescott (ed.) Clinical aphasiology, (Vol. 21, pp. 323332) Austin, Tx: Pro-Ed.

Porch, B. E. (1967) . Porch index of communicative ability. (Vol. 2) - Palo Alto, CA: Consulting Psychologists Press.

Purdy, M.H., Belanger, S., \& Liles, B.Z. (1992) . Righthemisphere-damaged subjects' ability to use context in inferencing. In T. Prescott (ed.) Clinical

aphasiology, (Vol. 21, pp. 135-143). Austin, Tx: ProEd.

Rau, M. T., Kongsbak, U., Gordon, M., \& Graville, D. J., (1992). Right-and left-brain-damaged subject performance on a test of reading comprehension: The Nelson test revisited. In T. Prescott (ed.) Clinical aphasiology, (Vol. 21, pp. 157-163). Austin, TX: Pro-Ed.

Schuell, H. (1965). The Minnesota Test for the Differential Diagnosis of Aphasia. Minneapolis: University of Minnesota Press.

Stachowiak, F.J., Huber, W., Poeck, K. \& Kerschensteiner, M. (1977). Text comprehension in aphasia. Brain and Language 4 , 177-195.

Tomkins, C.A. \& Mateer, C.A. (1984). Factors influencing paragraph comprehension by subjects with left or right hemisphere involvement. In R.H. Brookshire (Ed.), Clinical aphasiology, (Vol. 14, pp.202-207). Minneapolis, MN: BRK Publishers.

Tseng, C.H., McNeil, M.R., \& Milenkovic, P. (1993). An investigation of attention allocation deficits in aphasia. Brain and Language, 45, 276-296.

van Dijk, T. A., \& Kintsch, W. (1983). Strategies of discourse comprehension. New York: Academic Press.

Webb, W. G., \& Love, R. J., (1983). Reading problems in chronic aphasia. Journal of Speech and Hearing Disorders, 48, 154-164. 
Wilcox, M.J., Davis, G.A., \& Leonard, L.B. (1978).

Aphasics' comprehension of contextually conveyed meaning. Brain and Language, $6,362-377$.

Wilkinson, L. (1986) - SYSTAT: The system for statistics. Evanston, IL: Systat Inc. 
APPENDIX A

HUMAN SUBJECTS COMMITTEE APPROVAL 

Project/Program Title Effects of Oral and Silent Reading on Performance of Left-Hemisphere Damaged Individuals
Using the Nelson Reating Stilts Test

Principal Investigator Akers. Paul B.A. Rau, Judy Ph.D.

VAMC Rortand, Oregon Review Date: April 6.1994

\section{COMMITTEE FINDINGS:}

1. The Information given in the Informed Consent under the Description of Research DYES by Investigator is complete, accurate, and understandable to a research subject or a $\square$ No surrogate who possesses standard reading and comprehension skills.

2. The informed consent is obtained by the principal investigator or a trained and supervised designate under sultable circumstances.

3. Every effort has been made to decrease risk to subject(s)?

5. If subject is incompetent and surrogate consent is obtained, have all of the following conditions been met; a) the research can't be done on competent subjects; $b$ ) there is no risk to the subject, or if risk exists the direct benefit to subject is substantially greater; c) If an incompetent subject resists, he will not have to participate; d) If there exists any question about the subject's competency, the basis for decision on competency has been fully described.

6. If the subject is paid the payment is reasonable and commensurate with the

\section{Comments: (Indicate if Expediced Review)}

Initial Review (Approved with Modifications) Signature of Chair indicates modifications have been made and the study may begin. If the R\&D Committee reverses this decision at their next scheduled meeting (May 16. 1994) you will be notified immediately.

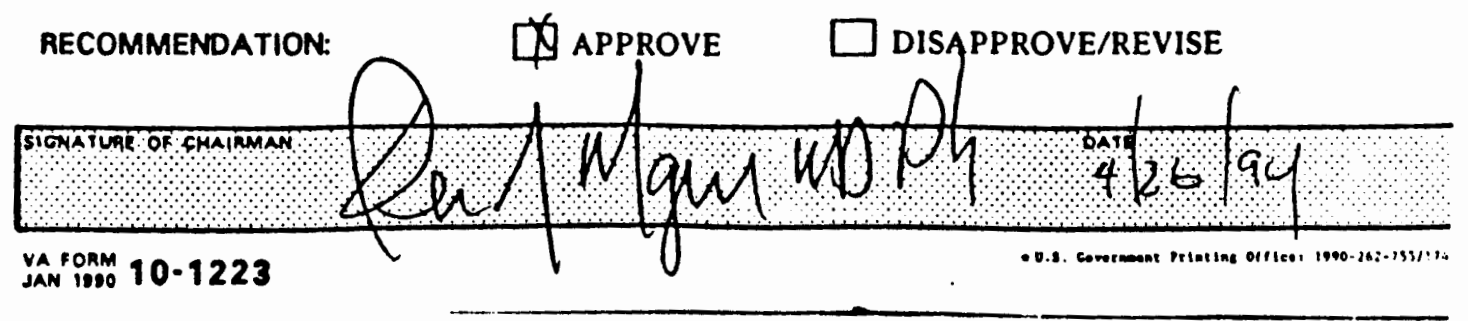


DATE: June 14,1994

TO: $\quad$ Paul Akers

FROM: for Martha Balshem, Chair, HSRRC, 1993-94 Reading on Performance of Left-Hemisphere Damaged Individuals Using the Nelson Reading Skills Test"

Your proposal is exempt from further HSRRC review, and you may proceed with the study.

Even with the exemption above, it was necessary by University policy for you to notify this Committee of the proposed research and we appreciate your timely attention to this matter. If you make changes in your research protocol, the Committee must be notified.

c. Office of Graduate Studies 
APPENDIX B

CONSENT FORMS 
Paul Akers, B.A.

Marie T. Rau, Ph.D, CCC-SLP

Speech Language Pathology

Portland, VA Medical Center

Portland, OR 97207

(503) 220-8262 Ext. 5717

Effects of oral and silent Reading on the Reading

Comprehension Performance of Left-Hemisphere Damaged

Individuals

Consent Form

1. The purpose of this study is to gather information on the reading comprehension of subjects who have suffered a stroke to the left side of the brain. I understand that I was selected for this study because I have been diagnosed with a stroke.

Paul Akers has explained the details of the study. The procedure involves reading, in the prescribed manner, five passages and answering the questions following each passage by pointing to the correct answer.

I understand that I will be informed of any changes in the nature of the study or in the procedures, as described above, as they may occur. Paul Akers will answer any and all questions that $I$ have.

2. I understand that there is no physical risk or discomfort involved.

I understand that there is no benefit of this procedure to me, but that the study may help to better understand how reading comprehension is affected in subjects who have suffered a stroke.

3. I consent to the use of the results in aggregate for publication for scientific purposes. The researchers have promised that my name and identity will be kept confidential.

4. I understand I may withdraw from the study at any time without prejudice or without prejudice to any VA benefits.

Every reasonable effort to prevent any injury that could result from this study will be taken. In the event of physical injuries resulting from the study, medical care and treatment will be available at the Department of Veterans Affairs Medical Center, Portland, oregon. For eligible veterans, compensation damages may be payable under 38 uSC 251 or, in some circumstances, under the Federal Tort Claims Act. for non-eligible veterans and non-veterans, compensation would be limited to situations where negligence occurred and would be 
controlled by the provisions of the Federal Tort Claims Act. For clarification of these laws, contact District Counsel (503) 221-3429. Although the researcher is a student at Portland State University (PSU), there is no compensation or treatment available from the state of Oregon or from PSU; and neither the state of oregon nor PSU assume responsibility if there is any injury as a result of this study.

5. I have not waived any legal rights or released the hospital or its agents from liability for negligence by signing this form.

6. Therefore having given consideration to the above information, I voluntarily consent to participate in this study as described.

If you have concerns or questions about this study, please contact the Chair of the Human subjects Research Review Committee, Office of Research and Sponsored Projects, 105 Neuberger Hall, Portland State University, (503) 725-3417.

Volunteer's Signature

Date

Witness's Signature

Date 
Subject Name:

Title of Study:

Date:

Effects of Oral and Silent Reading on Performance of Left-Hemisphere Damaged Individuals Using the Nelson Readin SkIIIS Test

Principal Investigator: Dr. Marie T. Rau, Ph.D,CCC-SLP VAMC: Portland

\section{Description of Research By Investigator}

PURPOSE: The purpose of this study is to gather information on the reading comprehension of subjects who have suffered a stroke to the left hemisphere of the brain.

PROCEDURES USED: As a participant in this study you will read a series of paragraphs in a prescribed manner (either aloud or silently). Following each paragraph, you will be asked to answer a series of questions pertaining to that paragraph. Some of these question may be answered directly from the reading while others will require you to make inferences in order to arrive at the correct response. You will indicate your response by pointing to the appropriate answer on the test sheet. You will also be given the opportunity to reread the passage and questions if you so choose. The test should take approximately 25 to 30 minutes to complete but you will be given as much time as you need.

DISCOMFORT OF ANI PROCBDURE: There are no physical discomforts associated with this study. You may experience some mild psychological discomfort as a result of frustration in answering test questions. Testing will be suspended if your level of frustration becomes too great.

EXPECTED BENEFITS OF TAE STUDY: You will derive no direct, personal benefit from this study. The information from this study will contribute knowledge which may lead to improved methods of evaluating and treating reading deficits associated with left-hemisphere brain damage.

Therefore, you may experience a degree of personal satisfaction as a result of your participation in this study.

Subject's Identification (I.D. plate or give Name-last, first, middle) 
Subject Name:

Date:

Effects of Oral and silent Reading on Performance of Left-

Title of Study: Hemisphere Damaged Individuals Using the Nelson Reading skills Test

Principal Investigator: Dr. Marie T. Rau, Ph.D,CCC-SLP VAMC: Portland

Withdrawal for the study: Your participation in this research study is voluntary,., and you may withdraw from this study at any time without prejudice to yourself or to any future medical care with this institution or with the Department of Veterans Affairs (VA).

Treatment in case of Infury, source of Additional Information: Every reasonable effort to prevent any injury that could result from this study will be taken. In the event of physical infuries resulting from the study, medical care and treatment will be available at this institution. For eligible veterans, compensation damages may be payable under 38 USC 251 or, in some circumstances, under the Federal Tort Claims Act. For clarification of these laws, contact District Counsel at (503) 326-2441. You have not waived any legal rights or released the hospital or its agents form liability for negligence by signing this form.

Any patient participating in a study at the Department of Veterans Affairs Medical Center, Portland, Oregon is encouraged to contact Dr. Dennis J. Mazur, Chairman, Subcommittee on Buman Studies to discuss any issues related to their research study participation. Dr. Mazur can be reached through the Research Service (503) $220-8262$ extension 6620 . Your signature below indicates that you understand that the Department of veterans Affair Medical Center, your investigators, and the sponsors of this research study bear no responsibility for any costs you may incur at other hospitals, clinics, or care institutions related to this study or to any of your medical conditions.

CONFIDENTIALITI: The results of your participation in this study may be used for publication or for scientific purposes, but your identity will not be disclosed unless you give separate, specific consent to this or unless as required by law. 
Subject Name:

Date:

Effects of Oral and silent Reading on Performance of Left-

Title of Study: Hemisphere Damaged Individuals Using teh Nelson Reading

Skills Test

Principal Investigator: Dr. Marie T. Rau, Ph.D,CCC-SLP VAMC: Portland

RESEARCH SUBJECTS' RIGHTS: I have read or have had read to me all of the above.

Dr. Rau has explained the study to me and answered all of my questions. I have been told of the risks and/or discomforts and possible benefits of the study. I have been told of other choices of treatment available to me.

I understand that I do not have to take part in this study, and my refusal to participate will involve no penalty or loss of VA or other benefits to which I am entitled.

The results of this study may by published, but my records will not be revealed unless required by law.

In case there are medical problems or questions, thave been told I can call Dr. RaU

at $220-8362 \times 57$ fúfing the day and Dr. Rase at 292-5018 after hours.

If any medical problems occur in connection with this study the VA will provide emergency care.

1 understand my rights as a research subject, and I voluntarily consent to participate in this study. I understand what the study is about and how and why it is being done. I will receive a signed copy of this consent form.

Signature of Subject

Date

Signature of Witness

Signature of Investigator
Witness (print) 
APPENCIX C

SHORT PORCH INDEX OF COMMUNICATIVE ABILITIES TEST PROTOCOL 


\section{SPICA}

Name

Case No

Date.

By

Time

10 Tolal Time

Test Conditions

Patient Conditions

\begin{tabular}{|c|c|c|c|c|}
\hline \multicolumn{5}{|l|}{ TIME } \\
\hline ITEM & 1 & VI & VII & $D$ \\
\hline \multicolumn{5}{|l|}{ 1. To } \\
\hline \multicolumn{5}{|l|}{ 2. $C_{6}$} \\
\hline \multicolumn{5}{|l|}{ 3. $\mathrm{Pn}$} \\
\hline \multicolumn{5}{|l|}{ 4. $\mathrm{KI}$} \\
\hline \multicolumn{5}{|l|}{ S. FI } \\
\hline \multicolumn{5}{|l|}{ 6. $Q$} \\
\hline \multicolumn{5}{|l|}{ 7. $\mathrm{PI}$} \\
\hline \multicolumn{5}{|l|}{ 8. $\mathrm{Mt}$} \\
\hline \multicolumn{5}{|l|}{ 9. Ky } \\
\hline \multicolumn{5}{|l|}{ 10. C } \\
\hline MODaLITY & VRO & CST & CST & C.PH \\
\hline \multicolumn{5}{|l|}{ Minutes } \\
\hline $\begin{array}{l}\text { MEAN } \\
\text { SCORE }\end{array}$ & & & & \\
\hline
\end{tabular}

Response Levels:

Overall.

\%oile

Note: 
APPENDIX D

EXAMPLE OF NRST PARAGRAPHS AND TEST QUESTIONS 
Long ago, people believed in monsters. The manticore was thought to have the head of a man, the body of a lion, and three rows of sharp teeth. It ate people if it caught them. The centaur, which lived in the forest, was believed to have the body of a horse but the shoulders, arms, and head of a man. Its voice sounded like the whinny of a horse. It hunted with a bow and arrows. A mermaid was said to have a fish's tail and a women's body. It lived in the ocean. People believed a ship would sink if it got too close to a mermaid. And almost everyone believed in dragons. Drawings of dragons showed some with wings, most with feet, and a few breathing fire. All of these monsters were considered dangerous. 
1. How did people probably feel about these monsters?
A. Afraid
B. Angry
C. Friendly
D. Puzzled

2. Which would be the best title?
A. Monsters in America
B. Monsters of Long Ago
C. Monsters That Fly
D. Monsters Then and Now

3. Which monster probably could swim best ?
A. Centaur
B. Dragon
C. Manticore
D. Mermaid 
4. Which monster didn't have the head of a person?
A. Centaur
B. Dragon
C. Manticore
D. Mermaid

5. Which monster had the body of a lion?
A. Centaur
B. Manticore
C. Dragon
D. It doesn't say.

6. Sailors were probably most scared of
A. centaurs.
B. dragons.
C. manticores.
D. mermaids.

7. Which monster hunted with a weapon?
A. Centaur
B. Dragon
C. Manticore
D. It doesn't say. 
Rodeo clowns make people laugh just as circus clowns do. However, their main job is to help save lives!

One event at a rodeo is bull riding. When a bull throws a rider, it usually turns around and charges. Somehow, the rider must escape those deadly horns. Then it's the clowns to the rescue! They wave their arms in front of the bull, displaying their bright, colorful costumes.

They also wave their hats. The bull then chases the clowns, giving the rider a chance to escape. But what about the poor clowns who are still in danger? A large barrel is kept in the center of the rodeo ring. If a bull gets too close to a clown, the clown makes a dive headfirst into the barrel. 
8. They means the
A. riders.
B. costumes.
C. rodeo clowns.
D. circus clowns.

9. The most important job of the rodeo clown is to
A. ride bulls.
B. scare bulls.
C. train bull riders.
D. protect bull riders.

10. What does the clown do when the bull gets too close?
A. Dives into a barrel
B. Runs to the exit
C. Waves at the bull
D. It doesn't say. 
11. Right after the bull throws the rider, the bull usually
A. charges.
B. gets away.
C. turns away.
D. goes after the clown.

12. This story is mainly about
A. rodeos.
B. rodeo clowns.
C. circus clowns.
D. bull riding. 
Each spring Adelie penguins return to a nesting ground that has many small stones. This place is called a rookery. Here each pair of mates builds a nest of stones. The male and female alternate collecting stones because if the nest isn't guarded, other penguins will steal the stones.

The female lays the eggs. Then her mate sits on them while she goes to the sea to eat and get fat. In about two weeks the female returns and the famished male goes to feed. She sits on the eggs for two more weeks until they hatch. 
13. While the male sits on the eggs, the female
A. gets hungry.
B. steals stones.
C. goes to the sea to eat.
D. builds a new nest.

14. About how long does it take penguin eggs to hatch?
A. 1 week
B. 4 weeks
C. 7 weeks
D. 10 weeks

15. After the eggs are laid, the male and female
A. collect food for each other.
B. take turns sitting on them.
C. leave them alone to hatch.
D. return together to the sea. 
16. Who is sitting on the eggs when they hatch?
A. Only the mother
B. Only the father
C. Both the mother
D. Neither the mother nor father and the father

17. To build a nest and hatch the eggs, male and female must
A. feed each other.
B. protect each other.
C. rehearse with each other.
D. cooperate with each other. 
18. Who gathers the rocks for the nest?
A. Only the male
B. Only the female
C. Both the male and female
D. Neither the male nor female

19. This selection is mostly about
A. rocky beaches.
B. nesting habits of penguins.
C. why penguins steal stones.
D. building nests in a rookery. 
When Beth's dog had seven pups last fall, Beth promised one to Judy. But Judy's mother said, "Since I work full time at the factory, I have no time to care for a dog. You can have a puppy only if you will take total care of it." This worried Judy because she had never had a pet before.

After she thought about it, Judy told Beth she didn't think she should take a puppy. "I don't know anything about taking care of a puppy," she said. "I don't know what to feed it. Who would groom it?" Judy was almost in tears.

"I can solve your problem," said Beth. "If you help me take care of the pups until they are weaned, you'll learn all you need to know."

Judy looked relieved. 
20. How many pups did the mother dog have?
A. 1.
B. 4
C. 7
D. It doesn't say.

21. Judy was near tears because

A. her mother didn't like pets.

B. Beth didn't think she knew about dogs.

C. she didn't want to care for a pet.

D. she didn't know how to care for a dog. 
22. Judy looked relieved because
A. Beth solved her problem.
B. Beth would let her have a puppy.
C. her mother would help with the puppy.
D. her puppy liked her.

23. Judy's mother wouldn't take care of a puppy because she
A. didn't'have time.
B. felt it was Judy's work.
C. had never had a pet before.
D. wanted Judy to learn responsibility. 
24. In the second paragraph, how did Judy probably feel?
A. Angry
B. Excited
C. Pleased
D. Frustrated

25. Who worked full time?
A. Beth
B. Beth's mother
C. Judy's mother
D. It doesn't say.

26. In what season of the year were the pups born?
A. Spring
B. Summer
C. Autumn
D. It doesn't say. 
Our coins are produced at places called mints that are owned and operated by the national government. Coins are made from slender bars of metal called ingots that are purchased by the government from mining companies. An ingot is flattened on a large machine called a rolling mill. The ingot is pressed between heavy rollers until it is just the correct thickness.

Next this strip of metal is put into a machine that cuts disks from it. Each disk, called a blank, is the same size as a coin. After each blank is polished, its edges are raised slightly in another machine. Finally the design is stamped on each blank by a machine called a press.

After the coins are weighed, inspected, and counted, they are sent to banks all over the country. 
27. What does a rolling mill do?
A. Flattens ingots
B. Raises edges
C. Stamps designs
D. It doesn't say.

28. Finished coins are sent to
A. mints.
B. banks.
C. polishers.
D. inspectors.

29. Mints belong to the
A. banks.
B. workers.
C. mining companies. D. federal government. 
27. What does a rolling mill do?
A. Flattens ingots
B. Raises edges
C. Stamps designs
D. It doesn't say.

28. Finished coins are sent to
A. mints.
B. banks.
C. polishers.
D. inspectors.

29. Mints belong to the
A. banks.
B. workers.
C. mining companies. D. federal government. 
APPENDIX E

TEST INSTRUCTIONS 


\section{Instructions:}

1) "I am going to have you read a series of short paragraph and some questions about what you have read. I will show you one paragraph at a time. I want you to read both the paragraph and questions aloud/silently.

2 ) Remember to read each paragraph and question aloud/silently. I would like you to indicate your response to each question by pointing to that answer on the card. You may reread the paragraph and questions if you wish in order to answer the questions.

3) I will be writing down your answers on this score sheet. I am not permitted to give you hints or comment on whether your answer is right or wrong. But, if you have questions during the session, feel free to ask them. I will let you know if I am able to answer your specific question.

4) When the session is completed, I will be happy to discuss how you did and answer any questions at that time.

5) Do you have any questions at this time? If you are ready we will begin. 
APPENDIX F

REVISED NRST SCORE SHEET 
NAME:

DATE:

LOCATION:

\begin{tabular}{|c|c|c|}
\hline \#ANSWER & RESPONSE & LEVEL \\
\hline 1. & & $\mathrm{H}$ \\
\hline 2. & & $H$ \\
\hline 3. & & $H$ \\
\hline 4. & & $L$ \\
\hline 5. & & $\mathrm{~L}$ \\
\hline 6. & & $\mathrm{H}$ \\
\hline 7. & & $T$ \\
\hline 8. & & $T$ \\
\hline 9 . & & $T$ \\
\hline 10. & & $L$ \\
\hline 11. & & $L$ \\
\hline 12. & & $\mathrm{H}$ \\
\hline 13. & & $\perp$ \\
\hline 14. & & $T$ \\
\hline 15. & & $T$ \\
\hline 16. & & $T$ \\
\hline 17. & & $\mathrm{H}$ \\
\hline 18. & & $T$ \\
\hline 19. & & $\mathrm{H}$ \\
\hline 20. & & $L$ \\
\hline 21. & & $\mathrm{H}$ \\
\hline 22. & & $\mathrm{H}$ \\
\hline 23. & & $T$ \\
\hline 24. & & $\mathrm{H}$ \\
\hline 25. & & $T$ \\
\hline 26. & & $T$ \\
\hline 27. & & $L$ \\
\hline 28. & & $L$ \\
\hline 29. & & $T$ \\
\hline 30. & & $L$ \\
\hline 31. & & $I$ \\
\hline 32 & & $\perp$ \\
\hline 33. & & $\mathrm{H}$ \\
\hline
\end{tabular}

